\title{
Anatomical Study of MRI Optic Chiasm at the Bamako Anatomy Laboratory
}

\author{
Babou Ba ${ }^{1 *}$, Siaka Diakité2, Abdoulaye Kanté1,3, Tata Touré1 ${ }^{10}$, Moumouna Koné1, \\ Nouhoum Ongoïba1,3, Abdel Karim Koumaré1,3, Siaka Sidibé ${ }^{2}$ \\ ${ }^{1}$ Laboratoire d'Anatomie et de Morphologie Clinique FMOS, Bamako, Mali \\ ${ }^{2}$ Service de Radiologie, CHU Point G, Bamako, Mali \\ ${ }^{3}$ Service de Chirurgie "B”, CHU Point G, Bamako, Mali \\ Email: ^babouba20022000@yahoo.fr
}

How to cite this paper: Ba, B., Diakité, S., Kanté, A., Touré, T., Koné, M., Ongoïba, N., Koumaré, A.K. and Sidibé, S. (2020) Anatomical Study of MRI Optic Chiasm at the Bamako Anatomy Laboratory. Forensic Medicine and Anatomy Research, 8, 11-17. https://doi.org/10.4236/fmar.2020.82002

Received: August 9, 2019

Accepted: March 8, 2020

Published: March 11, 2020

Copyright $\odot 2020$ by author(s) and Scientific Research Publishing Inc. This work is licensed under the Creative Commons Attribution International License (CC BY 4.0).

http://creativecommons.org/licenses/by/4.0/

\begin{abstract}
Roughly quadrangular, the chiasma presents many morphological variations. The optical chiasm, odd and symmetrical structure of the optical pathways, is a required passage of the axons of neurons for the visual pathways. Any modification of its morphology evokes a pathological process, generally tumoral. The quality of MRI images rivals that of anatomical slices. So the MRI is essential for the study of the chiasma. The aim of this work was to study the morphometry of the optic chiasm in patients addressed for cerebral MRI to the imaging department of the university hospital of the POINT-G, during the period from July 29, to November 30,2016 . All patients who had a normal examination of the optic chiasma, numbering 15 , were included in this study. In $86.66 \%$ of cases the chiasma had a quadrilateral form. Its average length was $8.73 \mathrm{~mm}$ and its average width was $13 \mathrm{~mm}$. The average thickness was $4.13 \mathrm{~mm}$.
\end{abstract}

\section{Keywords}

Optical Chiasma, MRI, Laboratory, Anatomy

\section{Introduction}

The optic chiasm constitutes a segment of the optical pathways, between the optic nerves in front and the optic tracts behind. It is a crossroad for nerve fibers that carry nerve impulses from the retina to the geniculate lateral bodies [1]. It is located above the pituitary lodge, under the dorsal part of the orbital gyri of the frontal lobes of the brain [2]. It belongs to the ventro-inferior wall of the third ventricle and has close relationships with the arterial circle of the brain [3]. With a roughly quadrangular shape, the chiasma has many morphological variations. 
It can have the shape of an X; to be more or less long, more or less broad, more or less thick. The angle formed by the chiasma and the bicommissural line of the brain is also variable. In particular, it is greater in young children than in adults. These variations are concretized by the measurements established by J. Lang [2] on anatomical parts:

- The average thickness measured on 106 cases is $3.41 \mathrm{~mm}$ (variations $2 \mathrm{~mm}$ to $7 \mathrm{~mm}$ );

- The average width measured on 272 cases is $11.57 \mathrm{~mm}$ (variations 8.5 to 15 $\mathrm{mm}$ );

- The average length measured on 276 cases is $6.57 \mathrm{~mm}$ (variations 4 to 11 $\mathrm{mm}$ ).

In France, [4] carried out direct measurements on magnetic resonance images of living subjects without morphological alterations (tumoral or atrophic). These measurements are performed on median T1-weighted sagittal sections, on which ventral and dorsal white commissures were clearly identifiable. The average length of the chiasma measured on 70 cases is $10 \mathrm{~mm}$ (variations of 8 to $12 \mathrm{~mm}$ ). The angle formed by the chiasma and the bicommissural line of the brain measured on 100 cases is 31 degrees (variations of 21 to 40 degrees). Because of this, MRI is essential for the study of the optic chiasm. The quality of MRI images rivals that of anatomical slices. The chiasma and all surrounding structures are highlighted in thin sections, joined if necessary, in any chosen orientation, without mobilization of the patient, or aggressive act. It is possible, among other things, to perform oblique sagittal sections along the axis of the optic nerve and to see its junction with the chiasma, axial sections in the plane of the chiasma, and thus highlight the whole chiasma, optic nerves, intracranial and optic tract [4]. Optical chiasma, an odd and symmetrical structure of optical pathways [5], is a necessary passage for neuronal axons for visual pathways. Any modification of its morphology evokes a pathological process, most often tumor (chiasmal glioma, compression by a pituitary tumor).

The functions of the optic chiasm can be altered by certain pathologies, the most frequent of which are tumors such as: the pituitary adenoma, the craniopharyngioma, the glioma of the thing optics. The optic chiasm can be reached during the endocranial expansion of the mucocele. These are the reasons that led us to undertake this study with the general objective of studying the morphological characteristics of the thing optics. The specific objectives were to describe the shape of the optic chiasm, to specify the dimensions of the optic chiasm, to measure the angle formed by the chiasma and the bicommissural line of the brain, to determine the distance between the tubercle of the saddle and the ventral edge of the chiasma optical and finally appreciate the distance between the optic chiasm and the superior pole of the pituitary gland.

\section{Material and Methods}

\subsection{Subjects and Scope of the Study}

The patients concerned were referred to the imaging department of the Point $G$ 
UHC by other brain MRI services during the period from July 29 to November 30, 2016. Inclusion criteria were all patients who had a normal examination of the optic chiasm, exclusion criteria were all patients with morphological impairment of the optic chiasm. Data such as reason for MRI, age, and sex were collected from the exam record or were included on MRI exam requests. Our study included 15 Malian nationals, including 8 men and 7 women, aged 8 to 68 , with an average age of 36 years.

\subsection{Study Techniques}

The acquisitions were performed in the sagittal, coronal and axial planes, without gadolinium injection on a siemens Avanto 1.5 Tesla. The sequences in Turbo Spin Echo T1 and T2 were used with reconstruction of the images in contiguous thickness from 5 to $6.5 \mathrm{~mm}$ thick. The measured parameters were the length, width, thickness of the chiasma, the angle formed by the chiasma and the bicommissural line of the brain, the distance between the chiasma and the superior pole of the pituitary gland on the median sagittal sections, coronal and axial. The shape of the chiasma has also been described.

\section{Results}

\subsection{Sociodemographic Aspect}

The average age was 36 years old with extremes of 8 and 68 years. The sex ratio was 1.1 in favor of the male sex.

\subsection{Morphological Characteristics of the Chiasma}

We observed that in $86.66 \%$ of the cases the chiasma had an $\mathrm{X}$ or quadrilateral form and in $6.67 \%$ a flattened $\mathrm{X}$ shape (Figure 1 ).

\subsection{Distribution of Chiasma Values (Figure 2)}

We observed an average optic chiasm length of $8.73 \mathrm{~mm}$ with extremes of 5 and $12 \mathrm{~mm}$, its width was $13 \mathrm{~mm}$ with extremes of 8 and $17 \mathrm{~mm}$. The average thickness of the chiasma was $4.13 \mathrm{~mm}$ with extremes of 2 and $8 \mathrm{~mm}$.

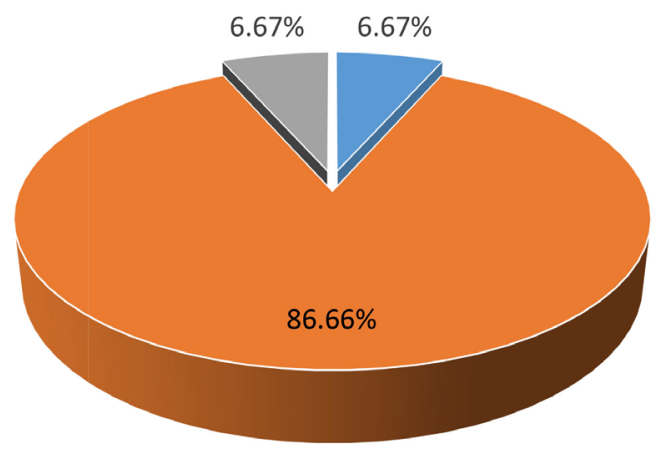

- X aplati ou à commissure $\quad$ X ou quadrilatère $\quad$ X allongé ou en $\mathrm{H}$

Figure 1. Morphological characteristics of the chiasma. 


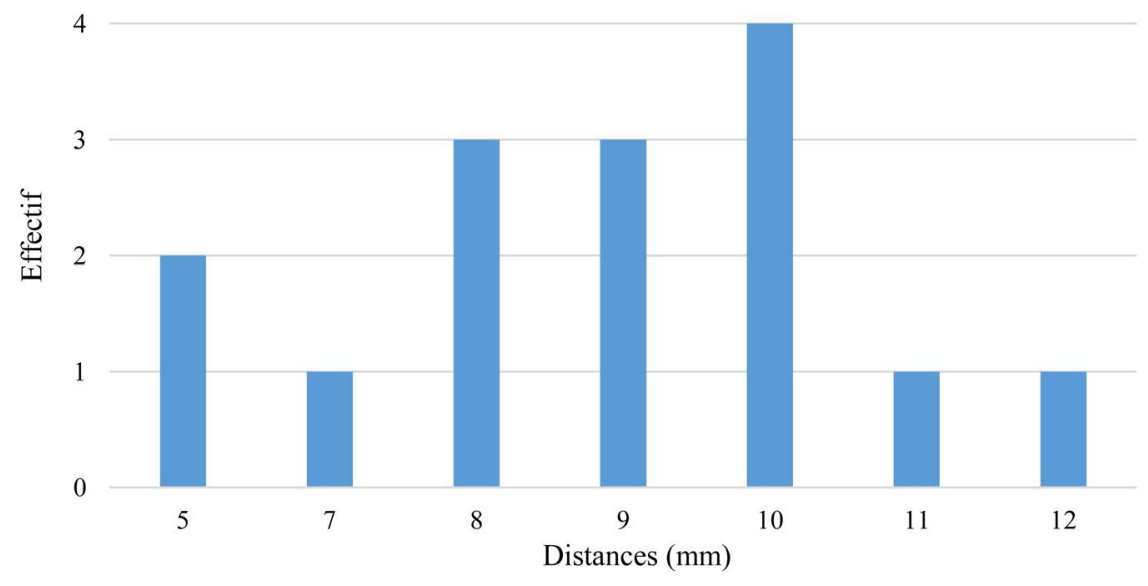

Figure 2. Distribution of chiasma values.

\subsection{Distribution of Values of the Angle Formed by the Chiasma and the Bi-Commissural Line}

The angle formed by the chiasma and the bi-commissural line varied from 16 to 38 degrees with a slight, the average angle was 26.26 degrees.

\subsection{Distribution of Values of the Distance between the Tubercle of the Saddle and the Ventral Edge of the Chiasma (Figure 3)}

The distance between the tubercle of the saddle and the turcic ventral edge of the chiasma had varied $6-7 \mathrm{~mm}$, with a mean distance $6.28 \mathrm{~mm}$.

\subsection{Distribution of Values of the Distance between the Chiasma and the Superior Pole of the Pituitary Gland (Figure 4)}

The distance between the chiasma and the superior pole of the pituitary gland was 3 to $9 \mathrm{~mm}$ with an average distance of $5.33 \mathrm{~mm}$.

\section{Discussion}

It has been established that an $8 \mathrm{~mm}$ section slice, using 2 signals on average, is suitable for the morphological study of the optic chiasm. The optimal technique for the anatomical study is SE 30/500, which also allows data in T1 sequence. The medial sagittal section provides the best picture of changes in the size of the optic chiasm and intracranial portions of the optic nerves. The coronal sections allow the best appreciation of the optical chiasm ratios and the axial sections are optimal to appreciate the retro-chiasmatic optical pathways [6].

We made section slices 5 to $6.5 \mathrm{~mm}$ thick. This is a highlight of our work. It should be noted that one of the weak points of this work was the fact that we did not have a large sample because of MRI machine failures. The device broke down four months after the start of our investigation. The average age of our patients was 36 years old with extremes of 8 and 68 years old. We had 4 patients (26.7\%) with an age between 1 and 20 years whose growth of the central nervous system is not completely complete. Eleven patients were over 20 years old, representing 


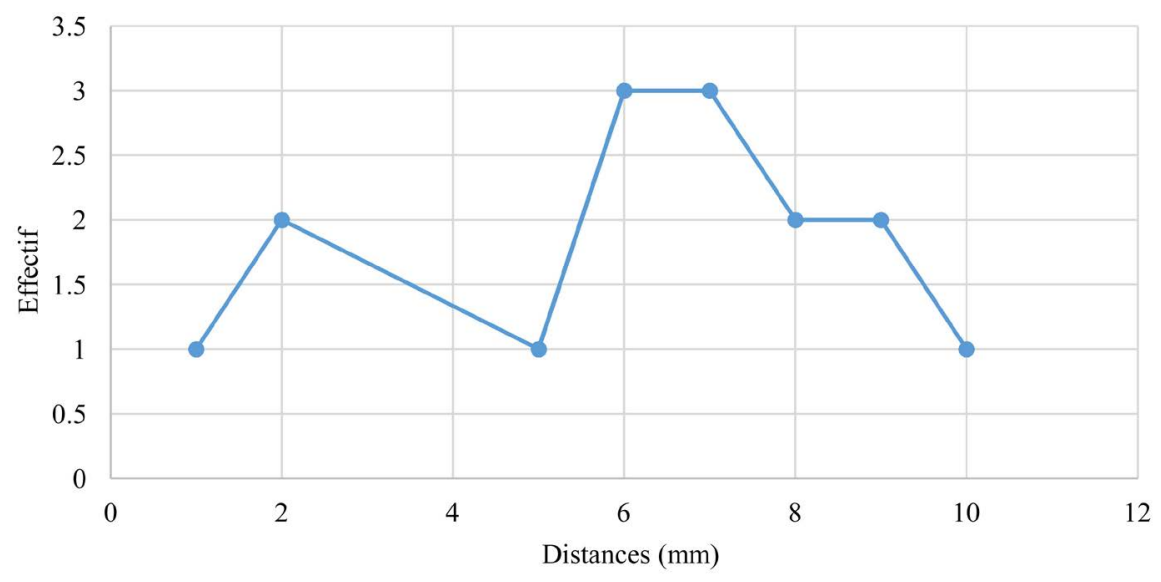

Figure 3. Distribution of values of the distance between the tubercle of the saddle and the ventral edge of the chiasma.

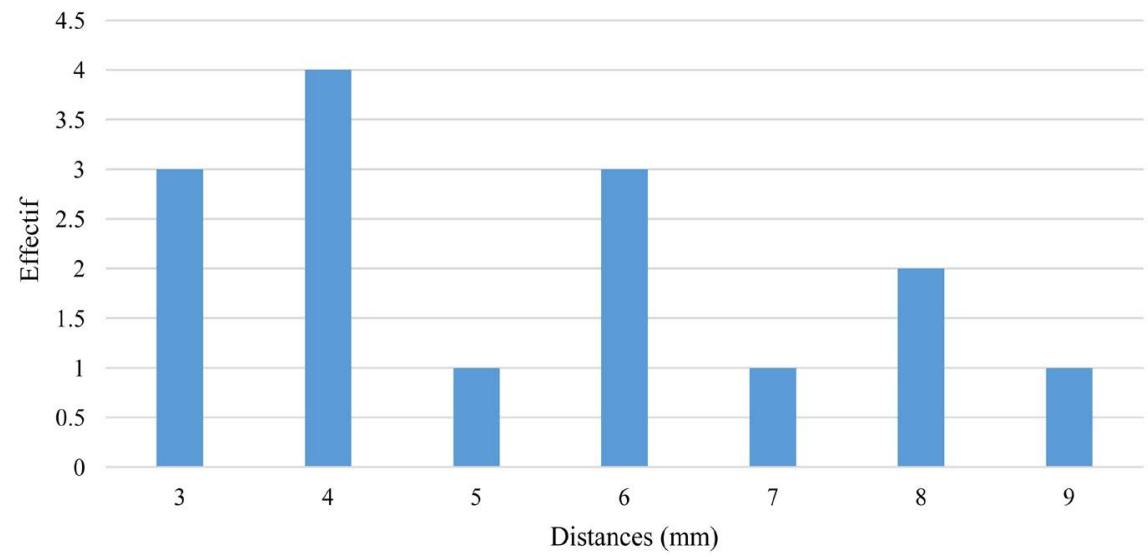

Figure 4. Distribution of values of the distance between the chiasma and the superior pole of the pituitary gland.

the majority of our series with a male predominance. In $86.66 \%$ of the cases the chiasma had a form in $\mathrm{X}$ or quadrilateral (average situation) in our series. This is consistent with data from the literature [1].

In our study the average length of the optic chiasma was $8.73 \mathrm{~mm}$ with variations of 5 to $12 \mathrm{~mm}$. Le Marec and Vignaud [4] noted an average length of 10 $\mathrm{mm}$ out of 70 cases, with variations of 8 to $12 \mathrm{~mm}$. J Lang reported on 276 cases of anatomical pieces, an average length of $6.57 \mathrm{~mm}$, with variations ranging from 4 to $11 \mathrm{~mm}$. We found an average width of $13 \mathrm{~mm}$ with variations of 8 to $17 \mathrm{~mm}$. J Lang reported on 272 cases of anatomical pieces, an average width of $11.57 \mathrm{~mm}$, with variations ranging from 8.5 to $15 \mathrm{~mm}$.

In our series the average thickness of the chiasma was $4.13 \mathrm{~mm}$ with extremes of 2 and 8. J Lang reported on 106 cases of anatomical pieces, an average thickness of $3.41 \mathrm{~mm}$, with variations ranging from 2 at $7 \mathrm{~mm}$ [4]. The angle formed by the chiasma and the bi-commissural line was 26.26 degrees with variations of 16 to 38 degrees. Le Marec and Vignaud reported [4] on 100 cases an average angle of 31 degrees with extremes of 21 and 40 degrees. 
We noted that the distance between the chiasma and the superior pole of the pituitary gland was 3 to $9 \mathrm{~mm}$ with an average distance of $5.33 \mathrm{~mm}$. This distance depends on age and hormonal status.

Studies have reported that the distance between the chiasm and the superior pole of the pituitary gland is variable, depending on the height of the gland and the appearance of its superior pole. In adolescent girls and women during periods of genital activity, the height of the pituitary gland can reach $12 \mathrm{~mm}$, with a convex but symmetrical upper surface. In pregnant women, the height of the gland can double and almost come into contact with the chiasma [1]. In our study the pregnancy parameter has not been studied. The distance between the optic chiasm and the superior pole of the pituitary gland may be a predictor of the extent of vision impairment related to a pituitary tumor. Ophthalmological signs by compression of the optic chiasm are sometimes the main clinical signs that lead the patient to consult in case of pituitary tumor [7].

The average distance between the tubercle of the saddle and the anterior edge of the optic chiasm was $6.28 \mathrm{~mm}$ in our series with variations of 1 to $10 \mathrm{~mm}$. It should be noted that this distance is a function of the shape of the optical chiasma. The longer the intracranial optic nerves are (H-shaped chiasm, post-fixed), the longer this distance is. Le Marec and Vignaud [4] reported on 70 medial sagittal sections of normal MRI a distance that varied from 1 to $8 \mathrm{~mm}$ with two peaks, one at $3 \mathrm{~mm}$, the other at 5 and $6 \mathrm{~mm}$ [4]. This distance can be a benchmark for the neurosurgeon to limit intraoperative incidents during the surgical approach of pathologies located in the vicinity of the chiasma and the pituitary gland [7].

\section{Conclusion}

The morphological characteristics of the optic chiasm studied by MRI are very close to the results of the cadaveric dissection. In $86.66 \%$ of the cases the chiasma had a form in X or quadrilateral. Its average length was $8.73 \mathrm{~mm}$ while its average width was $13 \mathrm{~mm}$. The average thickness of the chiasma was $4.13 \mathrm{~mm}$ with extremes of 2 and $8 \mathrm{~mm}$. The average distance between the tubercle of the saddle and the ventral edge of the chiasma was $6.28 \mathrm{~mm}$ while the average distance between the chiasma and the superior pole of the pituitary gland was $5.33 \mathrm{~mm}$. Despite the limited size of our sample, our results will contribute to enriching the literature. A similar study with a larger sample would be of interest.

\section{Conflicts of Interest}

The authors declare no conflicts of interest regarding the publication of this paper.

\section{References}

[1] Paturet, G. (1964) Traité d'anatomie humaine: Système nerveux (Tome IV).

[2] Gouazé, A. (1994) Neuroanatomie Clinique. 4th Ed., Expansion Scientifique Française, Paris, France. 
[3] Rizzo III, J.F. (1965) Embryology, Anatomy, and Physiology of the Afferent Visual Pathway.

[4] Le Marec, E. and Vignaud, J. (1993) Chiasma optique. EMC, Traité d'Ophtalmologie: 21-008-A-20. http://www.emc-consulte.com

[5] Risse, J.-F. (1999) Exploration de la fonction visuelle. Applications au domaine sensoriel de l'œil normal et en pathologie. SFO et Masson, Paris, France.

[6] Ana, A., Benjamin, C.P.L., Leslie, S.-L. and Michael, D.F.D. (1986) MRI of Optic Chiasm and Optic Pathways. American Journal of NeuroRadiology, 7, 2.

http://www.ncbi.nlm.nih.gov

[7] Carrim, Z.I., Reeks, G.A., Chohan, A.W., Dunn, L.T. and Hadley, D.M. (2007) Predicting Impairment of Central Vision from Dimensions of the Optic Chiasm in Patients with Pituitary Adenoma. Acta Neurochirurgica, 149, 255-260.

https://doi.org/10.1007/s00701-006-1108-7

https://link.springer.com 